\title{
DIREITOS HUMANOS, JUDICIALIZAÇÃO DA SAÚDE E DIÁLOGO INSTITUCIONAL: A EXPERIÊNCIA DE LAGES-SC, BRASIL
}

FelIPE AsensI

Professor Adjunto da Universidade do Estado do Rio de Janeiro (UERJ) e da Universidade Santa Úrsula (USU). Pós-Doutor em Direito pela Universidade do Estado do Rio de Janeiro (UERJ). Doutor em Sociologia pelo Instituto de Estudos Sociais e Políticos (IESP/UERJ). Mestre em Sociologia pelo Instituto Universitário de Pesquisas do Rio de Janeiro (IUPERJ). Advogado formado pela Universidade Federal Fluminense (UFF). Cientista Social formado pela Universidade do Estado do Rio de Janeiro (UERJ). Aperfeiçoamento em Direitos Fundamentais pela Universidad Complutense de Madrid (UCM), em Empreendedorismo pela University of Maryland (UM) e em Coaching pela University of Cambridge (UCA). Foi Visiting Scholar da Universidade de Coimbra (UC). Membro Efetivo do Instituto dos Advogados Brasileiros (IAB). Senior Member da Inter-American Bar Association (IABA). Membro Benemérito do Instituto Latino-Americano de Argumentação Jurídica (ILAAJ). Membro do Comitê Consultivo Nacional da Biblioteca Virtual de Saúde (BVS-Integralidade). Membro Titular da Red Iberoamericana de Derecho Sanitario (RIDS). Membro do Conselho Curador do PenseSUS (Fiocruz). Membro da Asociación Latinoamericana de Sociología (ALAS). Professor convidado da FGV, PUC e IBMEC. Email: felipedml@yahoo.com.br

ROSENI PINHEIRO

Professora adjunta do Instituto de Medicina Social da Universidade do Estado do Rio de Janeiro, coordenadora e líder do Grupo de Pesquisa do CNPQ LAPPIS Laboratório de Pesquisas sobre Práticas de Integralidade em Saúde e bolsista de produtividade CNPq nível 2. Concluiu o Pós-Doutorado em Direito pela PUC-RIO, em parceria com Università degli Studi del Piemonte Orientale Amedeo Avogadro (UNIPMN, Itália) em 2010 e o doutorado em Saúde Coletiva pela Universidade do Estado do Rio de Janeiro em 2000. Coordenadora do Doutorado Interistitucional IMS-UERJ e UEA CAPES 2014-2019. Membro da Comissão de Ciências Sociais e Humanas em Saúde da ABRASCO desde 2006, Parecerista ad hoc de periódicos da área na Scielo (American Journal Health; Interface, Revista de Saúde Publica, Cadernos de Saúde Publica, PHYSYS, Ciência \& Saúde Coletiva, Revista de Educação Médica, Sexualidade, Saúde e Sociedade Revista Latino Americana do CLAM Centro Latino Americano de Sexualidade e Gênero ) e membro do conselho editorial da Revista Interface, Ciência \& Saúde Coletiva, Revista Eletrônica de Comunicação, Informação e Inovação em Saúde do ICICT/FIOCRUZ, Conselho Cientifico Caderno Saúde Coletiva UFRJ, e Parecerista das FAPS: FACEPE, FAPEAM, FUNTAC, FAPEMIG. É coordenadora da Biblioteca Virtual Integralidade Saúde 
BIREME/PAHO/OPAS/OMS, que objetiva sistematiza a produção intelectual sobre o tema Integralidade no campo da saúde. Participante do PROCIÊNCIA (Programa de Incentivo à Produção Científica, Técnica e Artística) da UERJ a partir de 2006. Email: rosenisaude@uol.com.br

\section{Resumo}

A judicialização do direito à saúde tende a ser pensada sob o prisma da propositura de açóes judiciais, mas existe uma série de estratégias extrajudiciais que podem ser desenvolvidas com a presença do Judiciário. O objetivo deste artigo consiste em analisar a interação entre o Judiciário, os profissionais de saúde e a gestáo na efetivação do direito à saúde. Para tal, foi realizada uma pesquisa em parceria com o Conselho Nacional de Justiça em 2013 e 2014 no município de Lages-SC, Brasil, que buscou analisar as estratégias locais desenvolvidas. A experiência de Lages versou sobre o Núcleo de Conciliação de Medicamentos que, a partir da interação com o Consórcio Intermunicipal e com os atores políticos e jurídicos, passou a ser ferramenta de diálogo institucional. Estes arranjos permitiram uma atuação predominantemente extrajudicial e fomentou o diálogo entre os diversos atores locais. $\mathrm{O}$ resultado foi a redução da litigiosidade e a ampliação de arranjos institucionais dialógicos.

\section{Palavras-chave}

Judicialização da saúde; Diálogo institucional; Processo judicial.

\section{Abstract}

The judicialization of health tends to be thought through the prism of the lawsuits, but there are lots of consensual strategies that can be developed within the Judiciary Branch. The purpose of this article is to analyze the interaction between the Judiciary Branch, health professionals and the representatives in ensuring the right to health. To this end, a research in partnership with the National Council of Justice was held in 2013 and 2014 in the municipality of Lages-SC, Brazil, which investigated the developed local strategies. The Lages experience was about the Conciliation Center for Medicines and its interaction with the Intermunicipal Consortium and the political and legal actors, which became an institutional dialogue tool. These arrangements allowed a predominantly extrajudicial action and fostered the dialogue between the various local actors. The result was the litigation reduction and the expansion of dialogical institutional arrangements.

\section{Key words}

Judicialization of health; Institutional dialogue; Lawsuit. 


\section{Introdução}

A relação entre saúde e direito revela, em termos sociológicos, um dos principais desafios do mundo contemporâneo. $\mathrm{O}$ paradigma formalista do direito, assim como o paradigma intervencionista da saúde, tem recebido nos últimos 20 anos reconfiguraçôes das mais diversas. Isto ocorre, dentre outros motivos, por razóes institucionais, tais como o fortalecimento da saúde como um direito, mas também por razóes culturais, na medida em que são constituídos espaços estratégicos de reivindicação, além de uma maior compreensão dos cidadãos a respeito dos limites e possibilidades de seus respectivos direitos. Mais propriamente, a aproximação entre campos tão sólidos e com pressupostos não necessariamente congruentes gera uma nova forma de concebê-los, que esteja calcada na interdisciplinaridade.

Qualquer esforço de reflexão sobre a "fusão de horizontes" entre direito à saúde, parafraseando Hans-Georg Gadamer (1999 [1960]), significa um esforço de ampliação da própria contribuição que estes campos podem oferecer. Atualmente, direito e saúde podem ser concebidos como campos integrados, interdependentes e mutuamente constituintes e constituídos um pelo outro. Em primeiro lugar, é possível afirmar que as relaçôes sociais sáo mediadas pela nossa concepçáo de sujeitos de direitos, de um lado, e de seres humanos, de outro. Portanto, enquanto sujeitos de direitos e seres humanos, não é possível afastar a relevância da relação entre direito e saúde na própria organização e funcionamento do "corpo social". Medicamentos, tratamentos, normas jurídicas e decisóes judiciais, antes de serem meros produtos institucionais, são oriundos de relaçóes sociais que se estabelecem em sociedades específicas e orientam as suas práticas sociais. De modo algum esta relação é isenta de contradições e desafios, sobretudo porque estamos tratando de campos com trajetórias científicas, culturais e políticas distintas.

No período pós-constituinte, que cristalizou as mudanças pelas quais as instituiçóes jurídicas passaram no Brasil, observa-se um crescimento considerável de pesquisas ${ }^{1}$ que buscam analisar a chamada judicialização, inclusive da saúde. No cenário contemporâneo, observa-se uma pluralidade de instituições, atores e intérpretes que também atuam decisiva e legitimamente na construção e garantia de direitos, especialmente na via judicial.

De "poder tímido", o Judiciário contemporâneo passou a ocupar uma centralidade considerável no processo de resolução de conflitos e efetivação de direitos. Como exemplo desta "timidez" institucional, é possível citar Barão de Montesquieu (1996 [1748]), que concebe o Judiciário como um mero intérprete da lei. Diante da impossibilidade fática da "lei falar por si só", seria preciso a figura de um ser humano para expressar o que consta

1 Dentre essas pesquisas, é possível destacar algumas publicaçôes que contribuem para a reflexão sobre as instituiçōes jurídicas no Brasil, tais como Vianna et al. (1999), Arantes (2002) e Cunha (2010) 
em seu texto, além de também estabelecer o alcance desta norma. Este ser humano, por ser investido da autoridade estatal de resolver conflitos e efetivar direitos, deve aplicar a lei contendo-se à sua literalidade. Conforme salienta Badinter, "assim como o juiz, porque ele é competente para resolver o conflito, para dizer o Direito, e que o Direito exprime, dentro de toda a sociedade, um sistema de valores, de modo que este juiz apareça como depositário e defensor destes valores" (Badinter, 2003, p. 10).

O Judiciário se apresenta como um ator importante no processo de efetivação de direitos, cuja proeminência, de fato, advém de suas competências e atribuiçôes constitucionais.. Porém, é preciso considerar que há outras formas de envolvimento de instituições jurídicas que não necessariamente ensejam a judicialização de conflitos, pois tais instituiçóes podem atuar independente da existência de processos judiciais.

É importante salientar que as concepçóes construídas pelos estudos de judicialização podem possuir limitaçóes de diversas naturezas para pensar o Judiciário no Brasil e em outros países. A assunção do juiz como a referencial primaz na efetivação do direito pode propiciar uma a supervalorização da dinâmica judicial. Tal valorização tem sido operada em detrimento de reflexôes sobre outras formas jurídicas e não-jurídicas de aplicação e efetivação de direitos, a exemplo a mediação extrajudicial.

É esta possibilidade de atuar de forma independente do Judiciário que permite a proeminência e o destaque de outras instituiçóes jurídicas - tais como a Defensoria Pública e o Ministério Público - na efetivação de direitos sociais e coletivos que exigem rápida prestação, tais como a saúde. Tão importante quanto o estudo dos fins de uma ação judicial, é o dos meios utilizados pelas diversas instituiçóes para efetivar direitos. Isso permite pensar uma nova forma de atuação das instituiçóes jurídicas que vai além da mera judicialização, o que amplia ainda mais as reflexôes sobre seu protagonismo no tocante à efetivação de direitos e implementação de políticas públicas.

Mais precisamente, as relaçóes sociais podem submeter-se tanto a uma juridicização (conflitos que não são levados ao Judiciário, mas que são discutidos sob o ponto de vista jurídico, principalmente em momentos pré-processuais) quanto a uma judicialização (conflitos que são levados ao Judiciário na forma de ação civil pública ou algum outro instrumento processual). Na medida em que há diversas instituiçóes jurídicas que não se utilizam necessariamente do Judiciário para realizar suas açóes, observa-se um contexto em que os conflitos são discutidos sob o prisma do direito, mas evita-se levar o conflito ao Judiciário - isto é, evita-se a judicialização do conflito ${ }^{2}$.

No Brasil, a superação da concepção de direito como expressão da lei também encontrou eco no que se convencionou denominar de doutrina brasileira da efetividade, que

2 Para um aprofundamento teórico e conceitual da ideia de juridicização, ver Asensi (2010). 
possui, dentre os seus expoentes, o jurista Luis Roberto Barroso. O argumento central desta perspectiva consiste no seguinte: para além da eficácia jurídica que uma norma possui, ou seja, a sua possibilidade de produzir efeitos num ordenamento jurídico porque formalmente válida, é preciso refletir sobre a eficácia social das normas, ou seja, a possibilidade de produzirem efeitos concretos no cotidiano das práticas dos atores sociais.

Ao partir do pressuposto de que o direito existe para se realizar, a ideia de efetividade significa o desenvolvimento concreto da função social do direito. "Ela representa a materialização, no mundo dos fatos, dos preceitos legais e simboliza a aproximação, tão íntima quanto possível, entre o dever-ser normativo e o ser da realidade social" (Barroso, 2006, pp. 82-83). Portanto, busca pensar o desenvolvimento dos direitos na prática, de modo a superar a perspectiva formalista que se traduz na mera eficácia jurídica. Isto se torna possível, inclusive, para pensar o direito à saúde numa perspectiva não-positivista e não-judicial.

O objetivo deste artigo consiste em analisar a interação entre o Judiciário, os profissionais de saúde e a gestão na efetivação do direito à saúde. Para tal, serão utilizados os dados de uma pesquisa que realizamos em parceria com o Conselho Nacional de Justiça em 2013 e 2014 no município de Lages-SC.

A cidade de Lages situa-se no estado de Santa Catarina e compóe um conjunto de municípios da serra catarinense. Os municípios da região enfrentam desafios de estruturação do sistema de saúde, especialmente porque estão distantes da capital Florianópolis, e também porque seus recursos são frequentemente desafiados para o fornecimento de serviços e insumos.

Em 1997, foi criado um consórcio intermunicipal que englobou 25 municípios e que existe até hoje. Do consórcio veio, em 2008, a assinatura de um Termo de Cooperação Técnica com o Judiciário, com o objetivo de estabelecer estratégias conjuntas de efetivação da saúde. Buscou-se, então, definir uma rotina de procedimentos para os processos judiciais referentes às prestaçóes de saúde. Em 2012, fruto deste termo, foi criado o Núcleo de Conciliação de Medicamentos, com o objetivo de proporcionar uma alternativa ao modelo adversarial da judicialização.

Desde entâo, os atores políticos e jurídicos empreenderam diversas açóes com o objetivo de definir critérios uniformes a serem aplicados na concessão de medicamentos e melhorar o gerenciamento do fornecimento dos medicamentos judiciais. Isto possibilitou o melhor atendimento aos usuários do SUS e ganhos operacionais aos municípios, por meio de diversas medidas implementadas de forma integrada. O resultado é a construção extrajudicial - a partir do Consórcio e do Núcleo - de diversas políticas públicas com a sinergia cotidiana entre o Executivo e o Judiciário.

No próximo capítulo, serão apresentados os aspectos metodológicos da pesquisa. Em seguida, serão analisados os resultados obtidos a partir da análise da interação entre 
Judiciário, profissionais de saúde e gestão. Por fim, a título de consideraçôes finais, serão apontados fatores de sucesso da experiência de Lages.

\section{A Pesquisa}

A pesquisa sobre a experiência de Lages esteve inserida num estudo multicêntrico desenvolvido nos anos de 2013 e 2014, com abrangência nacional, que buscou analisar o cenário da judicialização da saúde em parceria com o Conselho Nacional de Justiça. Para tal, foi desenvolvido um enfoque interdisciplinar a partir de uma estratégia metodológica que triangulou técnicas quantitativas e qualitativas de produção, coleta e análise de dados.

Em primeiro lugar, em parceria com o Conselho Nacional de Justiça, foi divulgada a todos os tribunais do país e à comunidade acadêmica uma Convocatória de Experiências de Efetivação do Direito à Saúde. Esta foi aberta à participação de todos os tribunais e magistrados do país que tenham desenvolvido algum tipo de experiência inovadora de efetivação do direito à saúde.

Os critérios de seleção das experiências foram: a) uma experiência por região do país; b) a experiência deveria ter como objeto o estabelecimento de uma política judiciária de saúde no nível local, municipal, estadual ou federal para a saúde pública ou para a saúde suplementar; c) a experiência poderia versar sobre estratégias judiciais ou extrajudiciais desenvolvidas pelo Judiciário; d) seriam valorizadas as experiências que tenham algum tipo de interlocução com a sociedade civil, a gestão de saúde, as agências reguladoras e as demais instituiçóes jurídicas; e) as experiências poderiam versar sobre a tensão entre ações individuais e coletivas de saúde e as estratégias que foram utilizadas; f) as experiências poderiam versar sobre a relação entre o público e o privado no sistema de saúde, considerando o financiamento em saúde, a dupla entrada e a atuação das agências reguladoras; e g) as experiências poderiam versar sobre alguma questáo de bioética cujo deferimento/ indeferimento pelo Judiciário provocasse impactos positivos ou negativos na saúde biopsicossocial do cidadão.

Com a seleção das experiências, dentre as quais o município de Lages-SC, foi realizada pesquisa qualitativa a respeito dos arranjos institucionais e sociais desenvolvidos para a ampliação do direito à saúde. Neste sentido, em Lages foram realizadas 25 entrevistas, sendo: sete com membros de instituiçóes jurídicas, dez com membros da gestão de saúde, seis com profissionais de saúde e duas com usuários do SUS.

\section{A Experiência de Lages-SC}

\subsection{Mútua Capacitação}

Um dos principais desafios à atuação das instituiçôes jurídicas na saúde diz respeito a seu desconhecimento técnico em relação aos assuntos específicos da saúde. Os relatos 
apontam a alta utilização da mútua capacitação. Antes de ser uma atividade solitária de autocapacitação do juiz, observa-se que a mútua capacitação entre os atores políticos e jurídicos foi a principal estratégia. Afinal, a interação entre estes atores durante anos permitiu que as deficiências de conhecimento de ambos pudessem ser reduzidas. Com a mútua capacitação, ainda que informal, esses atores passaram a se relacionar mais e com mais frequência, o que permitiu o diálogo institucional.

Esta mútua capacitaçáo contou com o protagonismo do Judiciário, que resultou na própria experiência deste município de efetivação extrajudicial da saúde. É muito comum nos relatos dos gestores a menção à importância do Judiciário para sua própria capacitação. O inverso também ocorreu, mas não na mesma intensidade nos relatos. Vejamos alguns:

Se vocês olharem o que está escrito na portinha da frente, está escrito "academia". Nós somos uma academia. Sempre foi muito forte esse viés desses projetos. [...] Elas chegam aqui, e o que eu quero delas é que sejam pessoas íntegras, até porque daqui a pouco o pai coloca o filho pra trabalhar com a gente. Então a gente precisa ter pessoas íntegras para que a gente possa depois com o conhecimento nós vamos atrás. Agora é que demos uma paradinha do curso, mas antes era muito frequente nós realizarmos cursos formais e informais. Era semanal praticamente. Nós trabalhávamos com um grupo muito grande. É o "Paternidade", "Isenção fiscal", era a turma de "Recursos", até no eleitoral nós fizemos projeto. Eu sou juiz eleitoral. Entáo todas as áreas a gente procura trabalhar na formaçâo. Porque se você traz o cara "top", ele não vai explorar pontos novos. Claro, depois o pessoal andou, o "Paternidade” é um exemplo (juiz).

Mas antes disso que eu venho de duas formaçóes bem diferentes, antes disso pra mim era completamente diferente, você não vem para a saúde e o judiciário não vem pra você. $\mathrm{O}$ que é da lei você resolva lá e o que é da saúde eu resolvo aqui. Entáo não havia essa interação, não tinha nem discussão. Na universidade, por exemplo, eu sempre fui presidente do DCE. DCE é uma coisa que é tudo. E o curso do direito no DCE é o maior, não vou falar o palavrão que tem, mas gosta de perturbar. Por outro lado, é o que trás mais pontos para discussão. Então eu aprendi muito também com o pessoal do direito na universidade, mas sempre separando a saúde do direito. Tinha um colega meu, Everton, que atualmente é advogado trabalhista, ele era excelente mesmo jovem que me orientava. E ele sempre dizia que, fazendo meu trabalho, eu deveria pensar também pelo lado da lei, entâo isso foi proveitoso, pois ele me ensinava. Nessa época eu comecei, mas muito sutilmente. Na verdade eu comecei a ver essa interação e perceber que não tem como dissolver mesmo foi com o juiz daqui que meu abriu os olhos. Tanto que quando ele montou o "Paternidade", tinha muito pessoal jurídico do direito e não deu certo, pois aí era exclusivamente o pensamento da lei, eles náo tinham o olhar da humanizaçáo, 
da importância do diálogo, de ouvir, do cuidado, eles não tinham isso. Quando ele juntou os dois foi aí que percebemos o quâo importante foi que aí começamos a discutir saúde e direito (funcionária do Núcleo).

Dos relatos acima, podemos extrair três elementos importantes. Em primeiro lugar, a autocompreensão do Judiciário de que ele realmente pode e deve capacitar as pessoas para que possam atuar na efetivação da saúde de maneira não adversarial. Em segundo lugar, a compreensão de que a formação é fundamental, daí a realização de cursos e oficinas com regularidade mensal para criar espaços de discussão. Em terceiro, observa-se o reconhecimento da contribuiçáo do juiz na formaçáo dos profissionais de saúde e dos gestores. Como se trata de uma cidade pequena e com interação cotidiana entre os atores políticos e jurídicos há anos, a mútua capacitação tem criado um espaço de respeito e de colaboração entre eles.

É interessante observar que a informalidade da capacitação trouxe maior flexibilidade para que fossem usados diferentes meios de capacitar, tais como reunióes, cursos, palestras, grupos de estudo, etc. Atualmente, as estratégias de capacitação são permanentes e desenvolvidas no âmbito do Consórcio Intermunicipal e no Núcleo de Medicamentos, alcançando até mesmo os agentes de saúde.

Em diversos relatos, há tendência dos atores políticos a aceitarem e acatarem os projetos e estratégias extrajudiciais advindos do Judiciário. Não é incomum identificar nos relatos o reconhecimento do Judiciário como partícipe da política pública de saúde, e isto não é diferente no que diz respeito à capacitação.

Inclusive, como se trata de uma relação estabelecida há anos, a participaçáo do CNJ nas açóes de capacitação não foi tão relevante como aconteceu em outras experiêncas no Brasil. Como a experiência de Lages foi se consolidando antes mesmo da existência do CNJ, ele não foi tão importante para seu desenvolvimento, apesar de ser visto como uma instituição fundamental para o Judiciário atual. Com o CNJ, foram criadas formas de discussão compartilhada das dificuldades do Judiciário em matéria de saúde, e a experiência de Lages passou a receber dimensão ainda maior. Vale dizer que, assim como o CNJ criou os Comitês Estaduais, seu modelo foi reproduzido em Lages com a criação de um Comitê Municipal de Saúde.

\subsection{A Construção do Projeto}

O principal objetivo do projeto foi a constituição de um espaço institucional de diálogo entre as instituiçóes jurídicas e políticas com o propósito de promover projetos extrajudiciais calcados na prevenção de problemas de saúde e na criação de um cotidiano colaborativo e compartilhado de efetivação do direito à saúde. $\mathrm{O}$ projeto é oriundo da 
constatação de que os atores políticos e jurídicos podem atuar de maneira integrada na efetivação do direito à saúde e independentemente da existência de processos judiciais.

Segundo relatos dos entrevistados, dentre os principais obstáculos identificados, observou-se, de um lado, a falta de compromisso dos gestores em desenvolver projetos de longo prazo e de maneira dialogada e, de outro lado, a falta de abertura do Judiciário em considerar a escassez de recursos, a dificuldade de compras de produtos e insumos, etc. Como resultado desta ausência de estratégias de pactuação para a efetivação da saúde, observou-se o crescimento da procura pelo Judiciário e um aumento da interferência das instituiçôes jurídicas no cotidiano da gestão.

O resultado foi um "caos administrativo", que se intensificou a partir da proliferação de mandados judiciais e da falta de padronizaçáo do seu cumprimento na gestão. Náo é por acaso que a experiência de Lages teve como uma de suas primeiras premissas a padronização de procedimentos e a racionalização da atuação dos atores políticos e jurídicos.

$\mathrm{O}$ interesse do Judiciário pela saúde partiu de uma experiência bastante pessoal do magistrado que coordenou do projeto. À diferença de outras localidades, em Lages o interesse não foi exatamente porque o juiz teve que decidir sobre o assunto, mas porque começou a despertar um interesse especial pela saúde em si e pelas possibilidades de atuar de maneira mais ativa e extrajudicial. Observe-se o relato abaixo, que evidencia a aproximação do juiz com a saúde não somente em razão da necessidade de decidir sobre o tema:

Acredito que foi entre 2004 e 2005, em razão dos processos judiciais. E no programa de qualidade, entre 1994 e 1995, pela saúde dos meus funcionários. Eu estava no tribunal de justiça e participei de um projeto em função da saúde do trabalhador do Judiciário. Então aquela minha experiência como juiz de direito em 1994 e 1995 num programa de qualidade onde você começa a trabalhar o gerenciamento numa questão mais global e não só uma visão muito específica, você tem que olhar o todo. Essas duas experiências e a do tribunal foram bastante ricas nesse sentido. Quando eu tive esses primeiros processos eu já senti essa questão da saúde. Entấo eu comecei a não verificar unicamente a consequência, mas trabalhar com a causa dessas questôes pra poder dar efetividade ao processo de saúde. O diferencial que eu vejo hoje do Judiciário é alterar o procedimento que o Judiciário tem com relação a essas demandas pra buscar efetividade. Porque se não buscar efetividade você está contabilizando apenas um dado e náo uma vida com qualidade.

O relato de uma gestora do consórcio também reforça que o projeto não nasceu somente da judicialização da saúde, mas de fatores extrajudiciais que possibilitaram maior diálogo entre o Executivo e o Judiciário. 
Nós começamos a detectar o alto índice de açóes judiciais. De vez em quando o secretário ligava desesperado pra mim dizendo que o juiz deu até às $18 \mathrm{~h}$, até o dia seguinte, senão ele seria preso. O juiz coordenador me perguntava e eu dizia como funcionava, e a gente sempre trabalhava em parceria. Às vezes o estado e o município não estavam conversando. O estado estava fornecendo o medicamento seis meses, e o outro era o município. Aí o paciente ficava correndo para todo lado. Nós começamos a conversar porque precisamos organizar isso. Vamos fazer um protocolo de intenção pra organizar. O paciente vem pedir o medicamento e temos o genérico disponível. Vamos conversar com o profissional que prescreveu pra ele pra ver se é possível. Se for pelo princípio ativo, pelo genérico, o farmacêutico mesmo pode trocar. Se for similar, náo. Se ele prescreveu um medicamento e tem um outro similar lá, é para ele dizer se pode ou não pode. Começamos a padronizar. Fizemos o primeiro protocolo. $\mathrm{O}$ paciente tinha que levar a receita atualizada e que precisava a cada 30 dias. E só a cada três meses ele vá ao especialista. Que tivesse um documento padrão que voltava para o médico responder antes de ir para o judicial. Que a equipe da farmácia estivesse bem informada sempre com uma lista sabendo o que é genérico e o que não é. Que fosse um atendimento humanizado. Tem uma fila, mas você está na minha frente. Agora eu vou olhar pra você e vou atender você. Não importa que a fila está grande. Depois o outro vai ser atendido da mesma forma, mas agora você é que interessa. Vou olhar pra você, vou chamar você pelo nome, vou explicar para você. Trabalhar com o funcionário que faça algo mais. Aí esse outro problema da questão da centralizada. A ideia é que centralize. E o juiz começou com essa ideia, vamos tentar. E ele insistia: "vamos fazer uma central de medicamentos judiciais. Porque se fosse o município que entregasse e fosse o estado estaria sempre ali. $\mathrm{O}$ paciente saberia que onde ele tem que buscar é ali”. E ele queria que fosse com o consorcio porque achava que se eu estivesse perto iria funcionar.

Sendo assim, o interesse pela saúde nasceu não somente da necessidade de se efetivar a saúde dos cidadãos, mas também em função da discussão sobre a própria saúde dos membros do Poder Judiciário. Trata-se de uma trajetória incomum na saúde, pois tradicionalmente os juízes despertam interesse maior sobre o tema por conta dos desafios presentes na atividade judicante. Isto reforça a preocupaçáo pela saúde para além de um processo judicial.

Não é por acaso que se buscou em Lages promover estratégias extrajudiciais diversas. Essa busca pelo extrajudicial náo ocorreu exclusivamente com a saúde, apesar de ter nela um exemplo visível. A aposta no desenvolvimento de projetos institucionais fez com que o Judiciário alcançasse em patamar fortemente proativo, o que foi decisivo para a consolidação da experiência. Os projetos tiveram como objetivo o aperfeiçoamento da atuaçáo do Judiciário e, dentre seus principais efeitos, é possível observar a valorização da atuação extrajudicial. 
Em 2006 e 2007, foram realizados diversos seminários sobre saúde, em que foram discutidos os desafios de efetivação e foi formado um grupo de trabalho para atuar na capacitação dos profissionais de saúde. Nessa época também se iniciaram as estratégias de capacitação de profissionais do direito através de encontros, reunióes de trabalho e workshops diversos. O relato abaixo de um juiz exemplifica como se iniciou o diálogo institucional:

Inicialmente foram reuniōes de trabalho com a exposição do problema e a gente começou a construir em conjunto essas soluçôes. Então geralmente eu tinha duas reuniôes por mês com os gestores de todos os graus e aí na sequência nós fomos intercalando com eventos científicos, workshops, seminários, oficina. A gente foi trabalhando pra gente criar. Aqui tem o material que vou passar pra vocês... é um grupo. Eu acredito que nesses seminários nós tínhamos 400 pessoas participando. Nós trouxemos o pessoal de Florianópolis e foi um dos momentos que a gente trabalhou. Então basicamente eu fazia uma portaria interna. Nós já tínhamos criado dentro desse processo aquele momento, aquela empatia com o fato de tá aproximando, de que o contato inicial partia da vara da fazenda para com eles. Então saía aqui do fórum e ia visitar as pessoas no local de trabalho. Aí depois trazemos pra cá e apontar um caminho. Esse apontar um caminho era muitas vezes de ouví-los também. Porque você tem que dar uma direção. As pessoas têm dificuldade pela falta de estrutura também no âmbito dos municípios e no estado por outras questóes de assumirem compromissos formais. Entáo eu fui criando de uma forma informal alguns trabalhos.

O relato de uma gestora do consórcio aponta que houve inicialmente a resistência política do Executivo. Ela informa que a "antiga administração, o antigo secretário, eles não queriam repassar o medicamento pra Central", que atualmente é denominada de Núcleo de Conciliação de Medicamentos. Posteriormente, a partir das diversas reunióes e encontros informais, de um lado, e das transiçóes políticas, de outro, a resistência política se converteu numa atitude mais colaborativa da gestão, o que permitiu a consolidação do diálogo institucional. Segundo uma gestora do consórcio:

Aquelas pessoas que na época não queriam contribuir, depois passaram a ser parceiros, começaram a ver com outros olhos. Porque começaram a ver as dificuldades voltando. Nós temos uma boa parceria com os gestores, mesmo com os anteriores que começaram a ver de uma outra forma. Os farmacêuticos tanto da outra administração quanto dessa começaram a entender e foram se comprometendo e começou a aumentar a parceria. Aí nós fomos buscando a $\mathrm{OAB}$ que é muito parceira. [...] A secretária atual tem um pouco mais de sensibilidade, ela foi muito tempo secretária municipal de Saúde. [...] Da mesma forma os advogados, os procuradores e os demais que entram com as açóes. Tanto é que o presidente da OAB é 
parceiro. Vai ser membro do comitê intermunicipal. Estamos em contato com a associação médica, dos farmacêuticos e bioquímicos, toda entidade privada e pública pra participar, conhecer e dar sua contribuiçáo. Estáo participando. [...] A nossa ideia é começar a investir no agente comunitário de saúde e lá na farmácia. E a parceria é bem mais significativa, não tem mais restrição.

Segundo os relatos, a vontade política não foi o único fator que permitiu a consolidação e o desenvolvimento da experiência. O "comprometimento" é algo comum nos relatos e permitiu que o diálogo institucional também fosse visto como uma oportunidade de aprendizado mútuo entre o Executivo e o Judiciário. A judicialização, que num primeiro momento foi encarada como um problema administrativo pelos gestores, passou a ser vista como um aprendizado e um sinal de que deveriam atuar preventivamente na resolução de conflitos e na efetivação da saúde. O relato abaixo, de um ex-secretário de Saúde, é exemplo disso:

Temo de avançar no sentido de ver algumas questóes que me preocupam, como por exemplo, quem são os advogados que judicializam? Será que não está tudo vindo de uma mesma fonte? Quais são os medicamentos? Porque isso tem de servir como fonte de alimentação das políticas públicas, então se está judicializando água mineral sem gás todo dia, vamos pegar essa água mineral e colocar na lista básica do município, desde que haja uma prescrição correta, tem de ter esse cuidado também.

Portanto, o modo como se construiu a relação entre os atores políticos e jurídicos em Lages fez com que se construissem novas formas de efetivação da saúde. Isto ocorre não somente em função do comprometimento destes atores com os diversos projetos realizados, mas também porque, durante anos, eles puderam interagir em diversos momentos e projetos, construindo um espaço de respeito e consideração mútuos. Conforme salienta uma gestora regional, "as pessoas vão ficando no projeto de diferentes formas".

\subsection{Estratégias Formais e Informais de Efetivação da Saúde}

A experiência de Lages possui estratégias formais e informais de efetivação do direito à saúde. Mesmo com os Consórcios e com o Núcleo, observa-se a existência de açóes judiciais no município, apesar de reduzidas drasticamente conforme foram sendo desenvolvidas as estratégias extrajudiciais.

Existe nas falas o reconhecimento de que a judicialização da saúde pode ter certa seletividade. Afirma-se que nem todos conhecem seus direitos e muitos outros não têm conhecimento da existência da Defensoria Pública ou possuem recursos para pagar os advogados privados. Os relatos apontam que o perfil do litigante em matéria de saúde pode ser "colonizado" pela classe média, que tem condiçóes mais favoráveis à litigação que as 
demais. Neste sentido, em Lages buscou-se compensar a seletividade do processo judicial com uma postura proativa e preventiva do Judiciário.

Não é por acaso que uma das principais preocupaçôes do início do projeto foi racionalizar o uso do modelo adversarial do Judiciário. Assim como foram estabelecidos critérios de racionalização do fornecimento de medicamentos, também foram criados parâmetros internos para as decisóes judiciais em matéria de saúde. O principal critério foi a disponibilidade prévia do medicamento na via administrativa, ou seja, se o medicamento está disponível no Núcleo, não haveria motivo para ajuizar uma ação judicial. A via administrativa seria mais rápida e satisfaria igualmente os direitos do cidadão, além de possibilitar a racionalização do uso do medicamento, conforme explicitado no item anterior. Conforme salienta um membro da gestão municipal de Lages, "o que já era disponibilizado não justifica uma ação".

Neste sentido, buscou-se, por exemplo, evitar açóes em duplicidade, que processavam o estado e/ou o município e/ou União para o mesmo medicamento. Além disso, buscou-se conferir maior resolutividade administrativa às demandas, tenham elas sido judicializadas ou não.

A busca por uma atuação mais informal também está relacionada ao reconhecimento de que o "tempo do processo judicial é diferente do tempo da saúde" e que existe certa inadequação entre a solução processual e as peculiaridades das demandas da população. O processo é binário e define quem será o vencedor e o perdedor, mas não auxilia necessariamente na efetivação do direito à saúde de maneira ampla, inclusive no que concerne a seus aspectos preventivos. O relato de um juiz é exemplo disso:

Imagine o doente tendo que esperar. $\mathrm{O}$ tempo dentro do processo não existe essa dimensão tempo. Mas o cara que tá do lado de fora ele conta em segundos, conta em minutos. Aqui a gente não tem essa noção de tempo, a gente tem etapa dos processos, tem fases e tem recursos, mas efetivamente a gente não sente dentro do processo o tempo. Então não dá pra você colocar demandas sociais dentro de um processo atemporal. Porque daí as pessoas ficam frustradas, as coisas não acontecem. A gente poderia pensar em outras alternativas.

A preocupação em resolver as demandas em saúde de maneira informal e extrajudicial é a tônica da experiência de Lages. O pressuposto é que o processo judicial não atende integralmente às demandas em saúde por conta do tempo de resolução, do tipo de decisão e do aparato institucional pouco aberto ao diálogo. Para efetivar a saúde, o pressuposto é o desenvolvimento de estratégias informais que sejam mais eficazes. Nas palavras do mesmo juiz, o processo seria o mesmo que o uso de um "canhão para matar uma mosca". O relato abaixo é revelador disso: 
Se ele trabalhar apenas com base no processo, não atende. Não atende porque é uma série de demandas. O processo fica muito caro. É como se você não tivesse a farmácia, nem o postinho de saúde e tivesse que ir sempre pra um hospital de alta complexidade. Quantas vezes a gente resolve lá às vezes com chá. Então eu penso que há meios alternativos, há soluçóes que são mais eficazes do que você sempre ter que ir pra mais complexa que é o Judiciário. Então você trazer um fato social no Judiciário sem ter tido essa outra possibilidade é como dar um tiro de canhão para matar uma mosca.

Vale dizer que o uso formal de procedimentos também encontra entraves no âmbito da gestão. Não bastaria um Judiciário mais informal se a gestão fosse completamente formalizada e burocrática. Neste sentido, tanto o Judiciário quanto o Executivo promoveram acordos e planos para que, independentemente de suas estruturas formais, adotassem estratégias informais que lhes garantissem maior flexibilidade, agilidade e adequação na efetivação da saúde. De práticas informais, o projeto se desenvolveu e, ao longo do tempo, foram formalizadas algumas estratégias, tais como o Consórcio e o Núcleo.

É interessante frisar que a estratégia informal foi uma questão de opção do Executivo e do Judiciário em Lages. Porém, isto não impediu a propositura de açóes judiciais, mas as reduziu substancialmente. Mas é relevante destacar que, desde 2009, a estratégia informal (e extrajudicial) deixou de ser uma questão de opção e se tornou a única estratégia possível do juiz coordenador da experiência. Isto porque se alegou suspeição desse juiz no julgamento de demandas de saúde pelo Ministério Público, julgada procedente pelo Tribunal de Justiça do Estado de Santa Catarina.

Sendo assim, desde 2009, esse juiz náo pode decidir judicialmente demandas de saúde, concentrando sua atuação no Consórcio e no Núcleo de maneira completamente extrajudicial. Mesmo a suspeição para julgar processos judiciais não impediu o estabelecimento de diversas estratégias entre os gestores e o juiz na efetivação da saúde, o que revela a vontade política e o comprometimento institucional desses atores. A seguir, o relato do juiz:

O tribunal declarou a minha suspeição. Eu tenho um acórdão aqui do tribunal, eu não posso trabalhar com processo de saúde, porque ao longo desse período eu tomei a iniciativa de criar esse espaço e o promotor arguiu a minha suspeição porque o entendimento dele no primeiro momento era que isso estava sendo feito para beneficiar o estado em detrimento do indivíduo. $\mathrm{Na}$ realidade, se você perceber o protocolo que foi criado, esse trabalho foi criado em prol do cidadão. Quer dizer não pra mim, diz por escrito para que eu possa levar para o juiz e o juiz vai designar um técnico, e o técnico vai dizer: "não, está fundamentado que esse caso aqui não é esse o caminho”. Então o papel que eu tive no primeiro momento é realmente um papel diferenciado do que se espera de 
um juiz. Então houve uma certa confusão porque esse é um papel de um cidadão, o que eu fiz foi o papel de um cidadão. Então não é normal para um juiz, mas isso é normal para um cidadão fazer. Eu, enquanto cidadão, tenho um dever com a minha consciência, eu não posso ver o paciente morrendo aqui na antesala com câncer e não fazer nada. $\mathrm{O}$ mínimo que eu tenho que fazer é ser educado, no mínimo eu tenho que levantar e cumprimentar, no mínimo eu tenho que pedir sobre a saúde dele. Agora se eu tenho o poder de fazer mais, como é que eu não vou fazer mais? Só por que eu sou juiz? Então não posso ter aquela conduta? Então isso foi entendido que eu estava ultrapassando as minhas atividades, eu estava me tornando parcial. Na verdade não, isso é uma questão de humanizar o atendimento. Agora eu vou entrar na sala de audiência e não vou te olhar? Não vou olhar pra ti? [...] Isso foi entendido de uma outra forma. Aí então o tribunal declarou e eu não aceitei. Aí foi pro tribunal e o tribunal disse: "ele é suspeito". Aí então eu não posso mais atuar desde 2009 em processos de medicamentos.

No caso de Lages, por conta da aproximação de anos entre o Executivo e o Judiciário, o próprio estado de Santa Catarina propôs recurso à decisão do tribunal para reverter a decisão. $\mathrm{O}$ relato abaixo explicita como se desenvolveu a questão:

Eu estava indo para um evento e estava em Rio do Sul, tocou meu celular. Era o procurador do estado à época. Ele diz então: "olha Doutor, eu tomei conhecimento aqui. Veja e obviamente que o grande condenado é o estado. O município e o estado". Entáo ele tá me ligando pra dizer: "olha, nós vamos recorrer daquela decisão, nós entendemos a sua posição e nós vamos recorrer a seu favor". Olha que coisa interessante. Eles recorreram mas não tiveram sucesso porque o recurso não foi pra frente, mas o estado no recurso ele diz: "Qual foi o problema do juiz? É que ele foi o primeiro a fazer”. Claro, o primeiro a fazer, daí ninguém entende. Hoje há dezenas de experiências, dezenas de situaçóes nesse sentido, então obviamente que daí fica diferente, mas o primeiro que faz corre esse risco. E eu não percebi essa situação e hoje penso até que a posição do tribunal é outra, mas foi uma decisão já mais antiga e nós estamos construindo, até com o auxílio de um outro colega, em algumas situações para eu passar a intervir, outras situaçôes que não envolvem o medicamento em si. Envolvem uma prótese ou uma cirurgia. Eu estou aos poucos assumindo essa parte, mas eu fiquei por alguns anos realmente afastado de todos os processos.

Segundo os relatos dos atores políticos e jurídicos, a declaração da suspeição não impediu que fossem estabelecidas estratégias extrajudiciais entre o Executivo e o Judiciário. Pelo contrário, serviu como "elemento motor" para que fossem criados diversos projetos em Lages com foco no diálogo institucional e na efetivação do direito à saúde. Conforme o juiz sustenta, seria "preciso pensar fora do quadrado", que é a atuação no interior de um processo judicial. Talvez isso tenha contribuído para as críticas que recebeu do Judiciário 
e das demais instituiçóes jurídicas no início do projeto, superadas com o tempo. Atualmente, mesmo o Ministério Público, que alegou a suspeição do juiz em 2009, trabalha de maneira mais integrada e colaborativa nos projetos desenvolvidos extrajudicialmente. "Pensar fora do quadrado" significa muito mais mediar e dialogar do que impor e decidir.

Segundo os relatos, o informal permitiria maior sensibilidade do julgador para entender os problemas suscitados, de modo a atuar na solução do problema como verdadeiro mediador. Esta compreensão de diálogo e de mediação foi fundamental para a experiência de Lages e para que as estratégias extrajudiciais tivessem efetividade. Exemplo disso foi uma greve dos médicos do hospital de Lages, da qual derivou a propositura, pelo Ministério Público, de uma Ação Civil Pública. A perspectiva da mediação e da sensibilidade esteve presente no caso concreto e foi decisiva para a resolução do conflito. Observe-se o relato do juiz:

Nós tivemos uma greve, uma notícia de greve dos médicos do hospital e aí houve uma atuaçáo do Ministério Público, uma ação civil pública. $\mathrm{E}$ aí eu entendi que não era o caso de eu determinar liminarmente que eles trabalhassem, porque eles trabalhando sem remuneração eu só iria adiar o problema. Entáo eu preferi fazer algumas audiências públicas pra entender o problema e nós nos encaminhávamos para uma solução pacífica. Nesse meio tempo, o Ministério Público apresenta uma reclamaçáo. Eu recebi uma determinaçáo pra em setenta e duas horas cumprir a determinaçáo e dar a liminar, examinar a liminar. Como eu estava num processo de negociação com os municípios da região para eles custearem uma parte desses serviços, a minha decisão saiu catorze dias depois. Um ano e meio depois nós conseguimos fazer um acordo e há três ou quatro anos hoje esse serviço vem sendo, hoje tem uma fonte de lançamento, resolveu o problema e o processo tá arquivado. Eu fui condenado, recebi uma advertência na minha ficha funcional limpa, agora tem uma advertência, porque eu descumpri a determinação de dar a liminar. Então o que acontece é que muitas vezes a sociedade espera que o juiz faça, mas se ele fizer a interpretação que é dada é outra. Porque o juiz ele é pra determinar o cumprimento da lei. Se você traz alguma outra metodologia de trabalho, aquilo é visto de uma outra forma. [...] Enquanto pacificador social eu tinha que resolver aquela questáo, encaminhar aquela questáo de forma efetiva. Se eu dou uma liminar eu iria causar na verdade um problema muito maior, porque daí eu ia liberar o hospital de remunerar o médico, o médico por outro lado ia se descredenciar, aí você perdeu a equipe e depois a gente percebe o que pode acontecer. Mas isso tudo eu não vejo de uma forma negativa. Muito pelo contrário, eu penso que todas essas experiências são extremamente positivas, extremamente ricas. Nós só aprendemos nessa dinâmica.

A preocupação em adotar uma nova metodologia que supere a lógica do processo não isentou o juiz de riscos e críticas, o que fez com que a atuação extrajudicial em Lages 
não fosse livre de contradiçóes. Independentemente disso, a vontade política foi fator fundamental para essa experiência, de modo que o apoio do Executivo ao juiz foi mais importante do que as instituiçóes jurídicas para que o projeto se iniciasse. Com o tempo, as instituições jurídicas se aproximaram, e alguns projetos foram até reproduzidos em outras localidades ou abraçados pelo CNJ.

\section{Conclusões}

A experiência de Lages foi formada a partir de uma vivência pessoal de interação entre o juiz e os gestores. Ao longo do tempo, esta relação informal se traduziu em estratégias eminentemente extrajudiciais de promoção, prevenção e recuperação da saúde, utilizando-se principalmente do Consórcio Intermunicipal e do Núcleo de Conciliação e com a participação de diversos profissionais de saúde.

Dentre os fatores de inovação da experiência, é possível destacar alguns no âmbito do Consórcio e outros no âmbito do Núcleo. No Consórcio, é possível citar a criação de um padrão comum de atuação em toda a regiáo, que evitou sobreposiçóes e racionalizou os gastos e investimentos. Além disso, destaca-se o diálogo do Judiciário com os gestores de saúde em prol de medidas efetivas de melhoria da comunicação formal/informal, que contribuiu para o estabelecimento de diversos projetos institucionais. Também é importante destacar a redução dos conflitos colaterais em decorrência da dificuldade de acesso à saúde pública com uma atitude proativa dos atores políticos e jurídicos que buscasse a prevenção, promoção e educação em saúde.

No Núcleo, é possível citar a verificação da real condição do paciente através de contato pessoal com este por meio de agentes comunitários de saúde especialmente capacitados pelo Núcleo. Indo além, observa-se a integraçáo dos usuários aos programas e medicamentos que são oferecidos pelo SUS e seu acompanhamento ao longo do tempo através do Núcleo. Não somente em relação aos usuários, mas observa-se também uma integração entre os órgãos da saúde (municipal e estadual) com o paciente, Defensoria Pública, advocacia pública e Ministério Público, além do Poder Judiciário. Observa-se ainda a agilidade nos procedimentos administrativos e nos processos judiciais, especialmente com a satisfação administrativa de diversas demandas de insumos, produtos e serviços. Por fim, destaca-se a conscientização dos agentes políticos quanto às políticas públicas de saúde e a mudança de mentalidade para a construção do diálogo institucional entre Executivo e Judiciário.

Neste sentido, a partir da experiência de Lages, podemos refletir sobre como os arranjos institucionais locais podem ser decisivos não somente para a construção de sentidos do direito à saúde, mas principalmente para a sua efetivação compartilhada. 


\section{Referências}

ARANTES, R. B. Ministério Público e Política no Brasil. São Paulo: Sumaré, 2002.

ASENSI, F. D. Indo além da judicializaçáo - O Ministério Público e a saúde no Brasil. Rio de Janeiro: FGV, 2010.

BADINTER, R. Introduction. In: BADINTER, R.; BREYER, S.; CASSESE, A.; DWORKIN, R.; GRIMM, D.; IGLESIAS, G. C. R. Les entretiens de Provence: le juge dans la société contemporaine. Paris: Fayard, 2003.

BARROSO, L. R. O Direito Constitucional e Efetividade de suas Normas - limites e possibilidade da constituição brasileira. Rio de Janeiro: Renovar, 2006.

CUNHA, J. R. (org). Direitos humanos e Poder Judiciário. Rio de Janeiro: FGV, 2010.

GADAMER, H. G. Verdade e método - traços fundamentais de uma hermenêutica filosófica. Rio de Janeiro: Vozes, 1999.

MONTESQUIEU, C. de S. O espírito das leis. São Paulo: Martins Fontes 1996.

WERNECK VIANNA, L. J.; CARVALHO, M. A. R. de; MELO, CUNHA, M. P. da; BURGOS, M. B. Judicializaçáo da política e das relaçóes sociais no Brasil. Rio de Janeiro: Revan, 1999. 